\title{
Increased Expression of Basement Membrane Components in Human Endothelial Cells Cultured in High Glucose
}

\author{
Enrico Cagliero," Michele Maiello, Daria Boeri, Sayon Roy, and Mara Lorenzi* \\ Eye Research Institute of Retina Foundation and Departments of Ophthalmology and ${ }^{*}$ Medicine, \\ Harvard Medical School, Boston, Massachusetts 02114
}

\begin{abstract}
Although the degree of hyperglycemia is a powerful and independent risk factor for diabetic microvascular disease, it has not been established if and how high glucose per se can induce the typical lesions of microangiopathy. We have investigated in human vascular endothelial cells the expression of messenger RNA (mRNA) for collagen type IV and fibronectin, the two glycoproteins characteristically increased in diabetic basement membranes. In 12 confluent primary cultures exposed for $11 \pm 1 \mathrm{~d}($ mean $\pm S D)$ to $30 \mathrm{mM}$ glucose and exhibiting cell number and thymidine incorporation similar to control cultures, the levels of collagen IV and fibronectin mRNA were, respectively, $238 \pm 140$ and $221 \pm 231$ percent of control $(P<0.01)$. The effects of high glucose were selective (the levels of collagen I and c-myc mRNA remained unchanged), independent of the proliferative activity of the cultures and of the plating substratum, and maintained throughout multiple passages. However, several days of exposure to high glucose were required before their appearance. These observations establish that high glucose is a perturbation sufficient to mimic the effects of diabetes on the regulation of basement membrane components and propose that modifications in gene expression may pertain to the chain of events leading to diabetic angiopathy.
\end{abstract}

\section{Introduction}

The fundamental structural lesion of the small blood vessels in diabetic patients is increased thickness of the basement membranes (1). While the disturbed metabolic environment appears to be critical for the development of this abnormality (2-4), it is unclear whether specific elements of the diabetic milieu play a preeminent causative role and, eventually, how they produce their effects. The epidemiologic observation that high blood glucose levels in diabetic patients are powerfully and independently associated with increased risk of microangiopathy (5-7), and the finding that hyperhexosemia unac-

Presented in part at the National Meeting of the American Federation for Clinical Research, Washington, DC, 29 April- 2 May 1988, and published in abstract form. (Clin Res. 36:478a.)

Address reprint requests to Dr. Lorenzi, Eye Research Institute, 20 Staniford Street, Boston, MA 02114.

Received for publication 2 May 1988.

J. Clin. Invest.

(c) The American Society for Clinical Investigation, Inc.

0021-9738/88/08/0735/04 \$2.00

Volume 82, August 1988, 735-738 companied by other metabolic abnormalities (as observed in experimentally galactosemic animals) results in thickening of retinal capillary basement membranes (8) and other characteristic lesions of diabetic retinopathy (9), propose high glucose as a potential inducer of at least some of the features of microangiopathy.

That exposure to high glucose is capable of altering the homeostasis of vascular endothelial cells (the cells that elaborate basement membranes) has been documented in our previous work (10-12). In particular, the finding that exposure to high glucose leads to DNA alterations in these cells (12) raises the possibility that changes in gene expression might occur. We have therefore examined in human umbilical vein endothelial cells whether exposure to high glucose in vitro alters the steady-state levels of messenger RNA (mRNA) for fibronectin and type IV collagen, the two glycoproteins characteristically augmented in diabetic basement membranes $(13,14)$.

\section{Methods}

Cell culture. Primary cultures of human endothelial cells harvested from individual umbilical veins (15) were plated in $60-\mathrm{mm}$ tissue culture dishes (Falcon Primaria, Becton Dickinson, Lincoln Park, NJ) at a cell density of $1.3 \times 10^{5}$ for controls and $1.7 \times 10^{5}$ for cells destined for high glucose treatment. The differential plating density was implemented to study experimental and control cells in the same assay at the same final density. This was not otherwise achievable owing to the replicative delay induced by high glucose $(10,11)$, and yet desirable when studying the level of fibronectin mRNA, known to be modulated by the proliferative state of endothelial cells (16). Cells were cultured as described (10) in medium 199 (Gibco Laboratories, Grand Island, NY) supplemented with $2 \mathrm{mM}$ glutamine, $17.5 \mathrm{mM}$ Hepes buffer, $14 \%$ heat-inactivated pooled human serum, $20 \mu \mathrm{g} / \mathrm{ml}$ endothelial cell growth supplement (Sigma Chemical Co., St. Louis, MO) and 90 $\mu \mathrm{g} / \mathrm{ml}$ heparin (Gibco), and containing penicillin $(50 \mathrm{U} / \mathrm{ml})$, streptomycin $(50 \mu \mathrm{g} / \mathrm{ml})$, and fungizone $(0.25 \mu \mathrm{g} / \mathrm{ml} ; \mathrm{Gibco})$. The medium in experimental dishes was supplemented with D-glucose (Fisher Scientific, Fair Lawn, NJ) from the day after plating (unless otherwise indicated) to achieve a final concentration of $30 \mathrm{mM}$. Glucose concentration in control cultures was $5 \mathrm{mM}$. To evaluate the time course of the effects of high glucose, some cultures were exposed to $30 \mathrm{mM}$ glucose for 24 or $48 \mathrm{~h}$ just before reaching confluency; others were passaged to successive subcultures being consistently maintained in normal or high glucose medium. A possible modulation of the effects of high glucose by the replicative activity of the cells was examined in cultures made quiescent by withdrawal of growth factors and reduction of serum to $2 \%$ for $36 \mathrm{~h}$; modulatory effects exerted by matrix components were investigated in cultures plated on fibronectin-coated dishes $(2.5$ $\mu \mathrm{g} / \mathrm{cm}^{2}$; Boehringer Mannheim, Indianapolis, IN). On the day of cell harvest for RNA isolation, cell number and pulse thymidine incorporation (17) were measured in two to three dishes for each treatment. 


$\begin{array}{lllllllll}5 & 30 & 5 & 30 & 5 & 30 & 5 & 30 & \mathrm{mM}\end{array}$

$R N A$ studies. Total RNA was extracted from confluent experimental and control cultures by the guanidine isothiocyanate method (18), and the RNA samples $(10 \mu \mathrm{g})$ were electrophoresed on $1 \%$ agarose gel containing $2.2 \mathrm{M}$ formaldehyde. The RNA was stained with acridine orange to document equal sample loading, transferred onto a nylon membrane (Schleicher \& Schuell, Inc., Keene, NH), and hybridized to ${ }^{32} \mathrm{P}$-labeled probes (Multiprime DNA labeling systems; Amersham Corp., Arlington Heights, IL) for human fibronectin (19), human collagen types IV (pro $\alpha-1)(20)$ and I (pro $\alpha-2)(21)$, and human c-myc (American Type Culture Collection, Rockville, MD). Hybridization was performed for $12-48 \mathrm{~h}$ at $42^{\circ} \mathrm{C}$ in a solution containing $50 \%$ formamide, $5 \times$ SSPE $(0.75 \mathrm{M} \mathrm{NaCl}, 5 \mathrm{mM}$ EDTA, and $50 \mathrm{mM}$ $\left.\mathrm{NaH}_{2} \mathrm{PO}_{4}, \mathrm{pH} 7.4\right), 2.5 \times$ Denhardt's $(0.05 \%$ each of bovine serum albumin, polyvinylpyrrolidone, and Ficoll), $0.1 \%$ SDS, and $100 \mu \mathrm{g} / \mathrm{ml}$ denatured salmon sperm DNA. The membranes were washed in $0.1 \times$ SSPE, $0.1 \%$ SDS at $55^{\circ} \mathrm{C}$, and exposed to Kodak XAR- 5 film at $-80^{\circ} \mathrm{C}$ for 24-36 h (fibronectin, collagen IV, c-myc) or $14 \mathrm{~d}$ (collagen I). Densitometry was performed with a Zeineh soft laser scanning densitometer.

High glucose-induced differences in signal intensity are expressed as percent of control (mean \pm SD). Statistical analysis was by the Wilcoxon signed-rank test.

\section{Results}

After $11 \pm 1 \mathrm{~d}($ mean $\pm \mathrm{SD})$ in primary culture the monolayers were confluent and the cell number $\left(\times 10^{6}\right)$ and pulse thymidine incorporation (cpm/ $10^{6}$ cells) were similar in control and experimental cultures, $2.7 \pm 0.9$ and $54,520 \pm 33,886$ for cells grown in physiologic glucose $(5 \mathrm{mM})$, and $2.5 \pm 0.8$ and $72,291 \pm 54,490$ for cells exposed to $30 \mathrm{mM}$ glucose, respectively. Total recovered RNA as determined by spectrophotometric reading at $260 \mathrm{~nm}$ was $9.1 \pm 2.5 \mathrm{pg} / \mathrm{cell}$ in control cultures and 10.5 \pm 4.0 in high glucose cultures. Fig. 1 shows a representative Northern blot analysis of RNA extracted from 4 of the 12 cultures and hybridized to ${ }^{32} \mathrm{P}$-labeled cDNA probes for human fibronectin, collagen type IV (pro $\alpha-1$ ), collagen type I (pro $\alpha-2$ ) and c-myc, a gene constitutively expressed in most dividing cells (22). Despite the variability shown by the different primary cultures in the level of these transcripts, consistent increases of the fibronectin and collagen type IV mRNAs were observed in the $30-\mathrm{mM}$ glucose cultures. As expected, and as documented by the need for prolonged exposure of the autoradiograms, the mRNA for collagen type I (interstitial collagen) was much less abundant than that of collagen type IV (basement membrane collagen), and, akin to the transcript for $c-m y c$, was not affected by high glucose concentrations. Densitometric quantitation of the mRNA changes induced by high glucose in the 12 primary cultures showed an increment of $221 \pm 231 \%$ for fibronectin $(P<0.02)$ and $238 \pm 140 \%$ for collagen type IV $(P<0.01)$, with no significant changes in the levels of mRNA for collagen type I $(81 \pm 30 \%$ of control) and c-myc (126 $\pm 39 \%$ of control) (Fig. 2).

3 of 12 primary cultures failed to show a response to high glucose (Fig. 2). This could not be attributed to different degrees of residual replicative activity, since in these cultures cell number and thymidine incorporation were well within the range for the group. Furthermore, in responsive cultures the effects of high glucose were equally obvious during proliferation and quiescence despite the lower basal levels of fibronectin mRNA expressed in proliferating cells (Fig. 3). The observation that acute exposure to high glucose ( 24 or $48 \mathrm{~h}$ ) was not sufficient to induce detectable changes in the level of fibronectin and collagen type IV transcripts (not shown) suggested that the effects of high glucose may require relatively prolonged exposure, and that the requirement may differ among geneti-

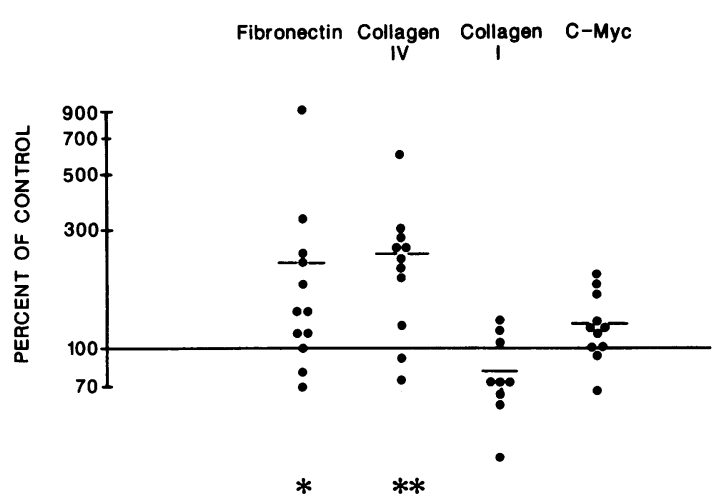

Figure 2. Densitometric quantitation of changes induced by high glucose (30 mM) in mRNA levels for fibronectin, collagen types IV and $\mathrm{I}$, and c-myc in 12 primary cultures of human vascular endothelial cells. Data are expressed as percentage of control; each point represents the mean percent change observed in two to four different blots from an individual culture. ${ }^{*} P<0.02,{ }^{* *} P<0.01$ compared with cultures grown in $5 \mathrm{mM}$ glucose. 


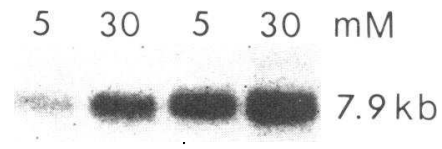

Figure 3. Northern blot analysis of human fibronectin in proliferating and quiescent vascular endothelial cells exposed to 5 or $30 \mathrm{mM}$ glucose. Cultures were maintained ei-

ther in the presence of $14 \%$ human serum, endothelial cell growth factor (ECGF) and heparin (left two lanes), or switched to $2 \%$ serum, no growth factors for $36 \mathrm{~h}$ before RNA extraction (right lanes). Under these conditions, pulse thymidine incorporation into DNA was reduced to $10 \%$ of control.

cally distinct sets of cells. Indeed, the batches of cells that failed to show an increment in fibronectin and collagen type IV mRNAs during primary culture manifested increases during the first subculture (Fig. 4), while the levels of collagen type I and $c-m y c \mathrm{mRNAs}$ remained unchanged by high glucose. We followed the behavior of the fibronectin and collagen type IV transcripts up to the third passage in seven cultures. Cells that had been consistently exposed to high glucose maintained in the third passage (36 $33 \mathrm{~d}$ in culture) significantly increased levels of mRNA for fibronectin $(282 \pm 172 \%$ of control, $P$ $<0.04)$ and for collagen type IV $(195 \pm 84 \%$ of control, $P$ $<0.04)$.

A possible modulation of the effects of high glucose by the substratum available to the cells was examined in cultures plated on fibronectin-coated dishes. Under these conditions, cultures exposed to high glucose continued to manifest a twofold increase in the mRNA levels for both fibronectin and collagen type IV when compared with controls.

\section{Discussion}

Our observations of increased mRNA levels for collagen type IV and fibronectin in endothelial cells exposed to high glucose establish that, among the many metabolic abnormalities of diabetes, high glucose is a perturbation sufficient to alter the biosynthetic characteristics of vascular endothelium in a fashion that mimics the effects of diabetes. It is, in fact, known that the increased collagen content of diabetic basement membranes results from increased synthesis $(23,24)$. The possibility that the increased amount of fibronectin originates from the trapping of the circulating glycoprotein secondary to abnormal properties of the matrix (25) cannot be excluded, but the recent demonstration of increased biosynthesis and processing of fibronectin by fibroblasts of diabetic animals (26) suggests

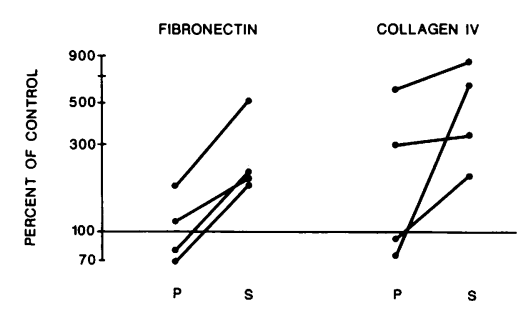

Figure 4. Quantitation of glucose-induced changes in fibronectin and collagen type IV mRNAs at the end of primary culture $(P$, $11 \pm 1 \mathrm{~d}$ of exposure to high glucose) and of the first subculture $(S$, $19 \pm 2 \mathrm{~d}$ of exposure to high glucose) in human vascular endothelial cells. Data are expressed as described in Fig. 2 legend. that the increased fibronectin content of diabetic basement membranes also might be the result of enhanced local production. Our data provide further support for this possibility.

The negative as well as the positive findings obtained with high glucose in vitro are compatible with the effects of diabetes. In accordance with the observations that collagen type I (interstitial collagen) is normally absent from vascular basement membranes and that its expression is not stimulated in the diabetic state $(13,27)$, we found only minimal expression of collagen type I mRNA in human endothelial cells and no changes upon exposure to high glucose. This and the lack of significant changes in the levels of $c-m y c$ mRNA also establish the selective nature of the endothelial cell response to high glucose.

The effects of high glucose on fibronectin and collagen IV mRNAs were independent of the proliferative state of the cultures and of the substratum on which the cells were plated. Once established, they were maintained throughout multiple passages, but several days of exposure were required before their appearance. This confirmed the intervening of a lag period between exposure to high glucose and occurrence of certain effects, a phenomenon already observed for the induction of cell cycle abnormalities (11). This latency may be due to the requirement for either a critical period of exposure to high glucose or for a critical number of cell doublings in the presence of high glucose. The latter would be necessary for the emergence of a sufficiently large population of cells with amplified genes, an event that could occur (28) in cells such as ours with a disturbed cell cycle (11). Another mechanism for the increased expression of the fibronectin and collagen IV genes that would be dependent upon a certain number of cell divisions is the loss of methylation in the specific DNA sequences, an event that can complicate forms of DNA damage (alkali-labile lesions and single-strand breaks) (29) that we have observed in vascular endothelial cells exposed to high glucose (12). Conversely, time of exposure to high glucose rather than number of cell divisions would be the critical factor should the increased expression of the genes under study be secondary to altered interaction with transcription-regulatory elements that have become modified by stable nonenzymatic glycosylation. In fact, within this scenario, the occurrence of cellular replication would substantially delay the appearance of the efferts. Time of exposure to high glucose, combined or not with cell division, would also be expected to be a determinant of the increased expression of fibronectin and collagen IV if the latter represents a response, or an adaptation to some other as yet unidentified cumulative disturbances of cellular or matrix components induced by high glucose.

Clarification of whether the increased mRNA levels for fibronectin and collagen type IV observed in the presence of high glucose result from transcriptional or posttranscriptional regulation will allow a first level of sorting among the mechanisms considered, and guide future questions and experimental strategies toward the reconstruction of the chain of events linking high glucose to diabetic vascular damage.

\section{Acknowledgments}

We thank Dr. M. Bourdon for the fibronectin cDNA clone and Dr. F. Ramirez for the collagens cDNA clones.

This work was supported by National Institutes of Health (NIH) grant HL-36861, the Juvenile Diabetes Foundation, The American 
Heart Association (California Affiliate), and the George and Frances Levin Endowment. E. Cagliero is the recipient of a Lions Clubs International Research and Development Award. M. Maiello was on leave of absence from Istituto Scientifico di Medicina Interna, University of Genova, Italy; and D. Boeri from Istituto Casa di Riposo, Genova, Italy.

\section{References}

1. Østerby, R. 1983. Basement membrane morphology in diabetes mellitus. In Diabetes Mellitus, Theory and Practice: 3rd Edition. M. Ellenberg and H. Rifkin, editors. Medical Examination Publishing Co, New Hyde Park, NY. 323-341.

2. Karam, J. H., M. Rosenthal, J. J. O'Donnell, E. Tsalikian, M. Lorenzi, J. E. Gerich, M. D. Siperstein, and P. H. Forsham. 1976. Discordance of diabetic microangiopathy in identical twins. Diabetes. 25:24-28.

3. Steffes, M. W., D. E. R. Sutherland, F. C. Goetz, S. S. Rich, and S. M. Mauer. 1985. Studies of kidney and muscle biopsy specimens from identical twins discordant for type I diabetes mellitus. N. Engl. J. Med. 312:1282-1287.

4. Bohman, S. O., G. Tyden, H. Wilczek, G. Lundgren, G. Jaremko, R. Gunnarsson, J. Ostman, and C. G. Groth. 1985. Prevention of kidney graft diabetic nephropathy by pancreas transplantation in man. Diabetes. 34:306-308.

5. West, K. M., L. J. Erdreich, and J. A. Stober. 1980. A detailed study of risk factors for retinopathy and nephropathy in diabetes. Diabetes. 29:501-508.

6. Weber, B., W. Burger, R. Hartmann, G. Hovener, R. Malchus, and U. Oberdisse. 1986. Risk factors for the development of retinopathy in children and adolescents with type I (insulin-dependent) diabetes mellitus. Diabetologia. 29:23-29.

7. Nathan, D. M., D. E. Singer, J. E. Godine, C. Hodgson Harrington, and L. C. Perlmuter. 1986. Retinopathy in older type II diabetics. Association with glucose control. Diabetes. 35:797-801.

8. Robison, W. G., P. F. Kador, and J. H. Kinoshita. 1983. Retinal capillaries: basement membrane thickening by galactosemia prevented with aldose reductase inhibitor. Science (Wash. DC). 221:1177-1179.

9. Engerman, R. L., and T. S. Kern. 1984. Experimental galactosemia produces diabetic-like retinopathy. Diabetes. 33:97-100.

10. Lorenzi, M., E. Cagliero, and S. Toledo. 1985. Glucose toxicity for human endothelial cells in culture. Diabetes. 34:621-627.

11. Lorenzi, M., J. A. Nordberg, and S. Toledo. 1987. High glucose prolongs cell cycle traversal of cultured human endothelial cells. Diabetes. 36:1261-1267.

12. Lorenzi, M., D. F. Montisano, S. Toledo, and A. Barrieux. 1986. High glucose induces DNA damage in cultured human endothelial cells. J. Clin. Invest. 77:322-325.

13. Falk, R. J., J. I. Scheinman, S. M. Mauer, and A. F. Michael.
1983. Polyantigenic expansion of basement membrane constituents in diabetic nephropathy. Diabetes. 32(Suppl. 2):34-39.

14. Weiss, M. A., B. S. Ooi, Y. M. Ooi, E. Engvall, and E. Ruoslahti. 1979. Immunofluorescent localization of fibronectin in the human kidney. Lab. Invest. 41:340-347.

15. Jaffe, E. A., R. L. Nachman, C. G. Becker, and C. R. Minick. 1973. Culture of human endothelial cells derived from umbilical veins. J. Clin. Invest. 52:2745-2756.

16. Jaye, M., E. McConathy, W. Drohan, B. Tong, T. Deuel, and T. Maciag. 1985. Modulation of the sis gene transcript during endothelial cell differentiation in vitro. Science (Wash. DC). 228:882-885.

17. Lorenzi, M., and S. Toledo. 1986. Myo-inositol enhances the proliferation of human endothelial cells in culture but fails to prevent the delay induced by high glucose. Metab. Clin. Exp. 35:824-829.

18. Chirgwin, J. M., A. W. Przybyla, R. J. MacDonald, and W. J. Rutter. 1979. Isolation of biologically active ribonucleic acid from sources enriched in ribonuclease. Biochemistry. 18:5294-5299.

19. Oldberg, A., E. Linney, and E. Ruoslahti. 1983. Molecular cloning and nucleotide sequence of a cDNA clone coding for the cell attachment domain in human fibronectin. J. Biol. Chem. 258:1019310196.

20. Weil, D., M. Bernard, S. Gargano, and F. Ramirez. 1987. The pro $\alpha 2(\mathrm{~V})$ collagen gene is evolutionary related to the major fibrillarforming collagens. Nucleic Acid Res. 15:181-198.

21. Myers, J. C., M. L. Chu, S. H. Faro, W. J. Clark, D. J. Prockop, and F. Ramirez. 1981. Cloning a cDNA for the pro- $\alpha 2$ chain of human type I collagen. Proc. Natl. Acad. Sci. USA. 78:3516-3520.

22. Thompson, C. B., P. B. Challoner, P. E. Neiman, and M. Groudine. 1985. Levels of c-myc oncogene mRNA are invariant throughout the cell cycle. Nature (Lond.). 314:363-366.

23. Brownlee, M., and R. G. Spiro. 1979. Glomerular basement membrane metabolism in the diabetic rat. Diabetes. 28:121-125.

24. Reddi, A. S. 1985. Collagen metabolism in the retina of normal and diabetic rats. Exp. Eye Res. 41:345-352.

25. Cohen, M. P., R. Saini, H. Klepser, and L. G. Vasanthi. 1987. Fibronectin binding to glomerular basement membrane is altered in diabetes. Diabetes. 36:758-763.

26. Phan-Thanh, L., L. Robert, J. C. Derouette, and J. Labat-Robert. 1987. Increased biosynthesis and processing of fibronectin in fibroblasts from diabetic mice. Proc. Natl. Acad. Sci. USA. 84:1911-1915.

27. Bruneval, P., J. M. Foidart, D. Nochy, J. P. Camillieri, and J. Bariety. 1985. Glomerular matrix proteins in nodular glomerulosclerosis in association with light chain deposition disease and diabetes mellitus. Hum. Pathol. 16:477-484.

28. Schimke, R. T., S. W. Sherwood, A. B. Hill, and R. N. Johnston. 1986. Overreplication and recombination of DNA in higher eukaryotes: potential consequences and biological implications. Proc. Natl. Acad. Sci. USA. 83:2157-2161.

29. Holliday, R. 1987. The inheritance of epigenetic defects. Science (Wash. DC). 238:163-170. 